\title{
Ética e pesquisa
}

\section{Taylor Brandão Schnaider *}

* Professor Titular Doutor do Departamento de Clínica Cirúrgica da Faculdade de Medicina da Universidade do Vale do Sapucaí. Presidente do Núcleo Pouso Alegre da Regional de Minas Gerais da Sobradpec

\section{RESUMO}

Objetivo: O presente artigo tem por objetivo explanar os aspectos éticos das experimentações em seres humanos e animais. Conteúdo: O tema abordado é de suma importância, pois almeja-se que o ser humano atinja seu bem-estar físico, mental, social e espiritual, sem esquecer os sagrados direitos dos animais. A maioria dos códigos internacionais que tratam das normas de pesquisa na área da saúde cita que a pesquisa desenvolvida em seres humanos deve estar fundamentada na experimentação prévia realizada em animais, em laboratórios ou em outros fatos científícos. O autor revê os conceitos de ética, pesquisa em seres humanos e experimentação animal. No que tange à experimentação humana, refere-se às Diretrizes Internacionais para Pesquisas Biomédicas Envolvendo Seres Humanos, à Declaração de Helsinki, às Leis Federais 8.080 e 8.142 de 1990, 8.974 de 1995 e a Resolução 196/96 do Ministério da Saúde. A seguir faz uma retrospectiva histórica acerca da primeira tentativa para se estabelecer normas em relação à pesquisa experimental em animais, ocorrida em meados do século 19, em Londres. É ressaltado que alguns critérios definidos àquela época persistem até o presente. A primeira Comissão de Ética em Pesquisa Animal foi criada na Suécia, em 1979 e, a seguir, nos EUA em 1984. No Brasil, os Comitês de Ética em Pesquisa Animal foram constituídos a partir da década de 90. Desde maio de 1979, existe a Lei Federal 6.638 que estabelece normas para a prática didático-científica da vivissecção de animais, não tendo sido regulamentada até a presente data. Além dela, tramitam no Congresso Nacional alguns anteprojetos dispondo sobre o uso de animais para atividades de ensino e pesquisa. Finalmente são apresentadas as normas adotadas pelo Colégio Brasileiro de Experimentação Animal. Conclusões: Os docentes, pós-graduandos, residentes e graduandos de uma Faculdade de Medicina, assim como graduandos dos Cursos da Área da Saúde, envolvidos em pesquisas realizadas em seres humanos e em animais, devem conhecer os princípios éticos que visam proteger os pesquisadores, os sujeitos da pesquisa e os animais selecionados para a realização de um trabalho científico.

Descritores: Ética em Pesquisa. Experimentação Humana. Experimentação Animal.

\begin{abstract}
Purpose: This research explains ethics aspects of experiments in animals and human beings. Contents: It is considered to be a very important issue because it focuses on the mental, spiritual, social and physical well being of humans, without forgetting the animal rights. The majority of the international health research codes mentions that human research must be based on previous laboratory animal testing or on scientific evidences. The author is reviewing the ethics concepts in humans and animal testing. He refers to the international policies for medical research on human beings, Helsinki Declaration, 8.080 and 8.142 of the 1990 federal law, 9.974 of the 1995 federal law and also to the 196/96 Health Department Resolution. Then, a historical retrospective is drawn about the first attempt to establish regulation on animal testing, which happened in the mid of the $19^{\text {th }}$ Century, in London. He also emphasizes that some of the criteria used at that time remains up to the present. The first ethics commission in animal testing was established in Sweeden in 1979 and in the United States in 1984. In Brazil, the ethics animal testing committees were established in the early 90s. Since May 1979, there is the 6.638 Federal Law which establishes regulations for the practice of animal use in research or teaching. This law is still waiting to be enforced. In addition to it, there are some drafts being analyzed by the Congress to regulate the use of animal for the purpose of teaching and researching. Finally the policies adopted by the Brazilian College of Animal Experiments are presented by the author. Conclusions: The professors, post-graduates, residents and medical students, as well as other students from health related courses enrolled in human and animal testing researches must be aware of ethics principles aiming to protect researchers, research subjects and the animals selected for scientific work.
\end{abstract}

Key words: Ethichs, Research. Human Experimentation. Animal Experimentation. 


\section{Pesquisa em seres humanos}

A pesquisa em seres humanos só é aceitável quando ela responde preliminarmente às conveniências do diagnóstico e da terapêutica do próprio experimentado, a fim de restabelecer sua saúde ou minorar seu sofrimento. Qualquer pesquisa que não vise a esses interesses é condenável. Se o ser humano tem pelo seu corpo um direito limitado, muito mais limitado é o direito do médico, cuja missão é preservar a vida até onde suas forças e a ciência permitirem. O médico deve ter, como norma irrecusável, um conjunto de princípios éticos e morais, inclinando-se mais para a vida, para a preservação da espécie e para a exaltação das liberdades fundamentais.

O Conselho para as Organizações Internacionais de Ciências Médicas (CIOMS), em colaboração com a Organização Mundial de Saúde (OMS), elaborou em 1993 as Diretrizes Internacionais para Pesquisas Biomédicas Envolvendo Seres Humanos, levando em conta a preocupação que a sociedade vem expressando com os novos aspectos éticos surgidos na investigação científica e na tecnologia biomédica ${ }^{1}$.

A Associação Médica Mundial, em sua 52a Assembléia realizada em Edimburgo/Escócia, em outubro de 2000, promulgou a Declaração de Helsinki VI, como uma proposta de princípios éticos que sirvam para orientar médicos e outros profissionais que realizam investigação médica em seres humanos. A próxima Assembléia será realizada em Seul/Coréia do Sul, em outubro de 2008.

A pesquisa colaborativa internacional e intercultural aumentou consideravelmente, envolvendo países em desenvolvimento, muitos dos quais ainda têm uma capacidade muito limitada para uma avaliação independente de projetos de pesquisa apresentados por seus próprios pesquisadores ou de outras nacionalidades.

Existe uma preocupação sobre a percepção da pesquisa biomédica envolvendo seres humanos como um benefício para seus participantes e a sociedade, e não como uma fonte de risco para os primeiros. Muitos vêem esta afirmação com apreensão, caso a pesquisa seja realizada ou promovida sem justificativas adequadas sobre os direitos e o bem-estar dos seus participantes.

Mais recentemente, de acordo com a Lei no 8.974 , de 5 de janeiro de 1995, regulamentaram-se os incisos II e V do $\S 1^{\circ}$ do Art. 225 da Constituição Federal, em que são estabelecidas normas para o uso das técnicas de engenharia genética e a liberação no meio ambiente de organismos geneticamente modificados. Ficam assim caracterizados os mecanismos de fiscalização e as normas de segurança na construção, cultivo, manipulação, transporte, comercialização, consumo, liberação e descarte de organismo geneticamente modificado, visando proteger a vida e a saúde do homem, dos animais e das plantas, bem como o meio ambiente.

Esse e outros fatos estão muito bem apresentados na Resolução $n^{\circ}$ 196, de 10 de outubro de 1996, referendada pelas atribuições conferidas pelas Leis ${ }^{\text {os }} 8.080$, de 19 de setembro de 1990 e 8.142 , de 28 de dezembro de 1990, do Conselho Nacional de Saúde, no capítulo destinado aos aspectos éticos da pesquisa em seres humanos, tendo-se em conta o respeito à sua dignidade e a proteção de seus direitos e bem-estar ${ }^{1,2}$.

Para realizar uma pesquisa em seres humanos, o pesquisador deve ter conhecimento dos requisitos essenciais para que a mesma esteja dentro de padrões éticomorais.

O Comitê de Ética em Pesquisa, um Colegiado interdisciplinar e independente, com "múnus público", deve existir nas Instituições que realizam pesquisas envolvendo seres humanos no Brasil. Foi criado para defender os interesses dos sujeitos da pesquisa em sua integridade e dignidade e para contribuir no desenvolvimento da pesquisa dentro de padrões éticos ${ }^{1,2}$.

O Comitê de Ética em Pesquisa também deve desempenhar um papel educativo, promovendo reuniões, seminários, mesas-redondas, grupos de discussão, criação de página eletrônica (site) e outros meios que possibilitem reflexão e discussão de temas éticos, casos com dilemas específicos e situações conflituosas ${ }^{1,2}$.

Sua constituição deverá incluir a participação de profissionais da área de saúde, das ciências exatas, sociais e humanas, incluindo, por exemplo, juristas, teólogos, sociólogos, filósofos, bioeticistas e, pelo menos, um membro da sociedade representando os usuários da instituição. Poderá variar na sua composição, dependendo das especificidades da instituição e das linhas de pesquisa a serem analisadas ${ }^{1,2}$.

A Resolução CNS 196/96, considera como pesquisas em seres humanos, as realizadas em qualquer área do conhecimento e que, de modo direto ou indireto, envolvam indivíduos ou coletividades, em sua totalidade ou partes, incluindo o manejo de informações e materiais. São também consideradas pesquisas envolvendo seres humanos as entrevistas, aplicações de questionários, utilização de banco de dados e revisões de prontuários ${ }^{1,2}$.

\section{Protocolo de Pesquisa}

Os documentos que devem compor o Protocolo de Pesquisa ${ }^{1-5}$ são: Folha de Rosto, Projeto de Pesquisa,Termo de Consentimento Livre e Esclarecido,Orçamento Detalhado

do Projeto de Pesquisa e o Curriculum vitae.

Folha de Rosto, com o Termo de Compromisso do Pesquisador e da Instituição em cumprir a Resolução CNS 196/96. Esse é o documento que dá consistência jurídica ao projeto, porque identifica o pesquisador responsável, a instituição e o CEP, que devem apor suas assinaturas e se comprometerem com o cumprimento das normas e com as responsabilidades correspondentes. O modelo da Folha de Rosto para Pesquisa Envolvendo Seres Humanos (versão outubro/99) pode ser encontrado na página da Internet do MINISTÉRIO DA SAÚDE, Conselho Nacional de Saúde, Comissão Nacional de Ética em Pesquisa - CONEP;

Projeto de Pesquisa, para que por meio dele sejam feitas a análise ética e a verificação da adequação metodológica. Projeto é a intenção de realizar algo, é um plano de ações. Consiste de uma descrição escrita e detalhada de uma pesquisa a ser realizada, não devendo exceder 20 páginas. Planejar significa elaborar um roteiro de ações a ser seguido, a fim de que sejam alcançadas as 
finalidades desejadas. Projetar significa antever e metodizar as etapas ou fases para a operacionalização de um estudo.

Os capítulos que devem compor o Projeto de Pesquisa são: Sumário, Introdução, Objetivo(s), Justificativa, Métodos, Referências , Anexos e Cronograma de execução.

Sumário - Facilita a consulta e a visualização da estrutura do projeto;

Introdução - Apresenta o tema, fornecendo uma visão geral do trabalho a ser realizado. Pode ser incluído um breve histórico e uma pequena revisão da literatura;

Objetivo(s) - Indica(m) o que se pretende com o desenvolvimento da pesquisa; dependendo da natureza do projeto, procede-se à apresentação do objetivo geral e dos específicos, separadamente;

Justificativa - Consiste na apresentação das razões de ordem teórica e/ou prática que justificam o trabalho de investigação que será desenvolvido. Devem ser considerados os objetivos e os benefícios que os resultados da pesquisa irão acarretar;

Métodos - É a parte do projeto onde se descreve a metodologia adotada para o desenvolvimento do trabalho. Descrição breve, porém completa e clara das técnicas e processos empregados, bem como o delineamento experimental. Deve conter:

Tipo de estudo: descritivo ou analítico (observacional ou intervencional);

Local: onde será realizado;

População: definir tipo, tamanho e formas de composição da casuística (amostra). Citar os critérios de inclusão e exclusão;

Intervenção: descrever todas as etapas referentes ao que será realizado ou aplicado. Nos estudos com animais incluir: período de adaptação; condições de confinamento (tipo e dimensões da gaiola ou compartimento, número de animais por gaiola, iluminação e aeração, temperatura e umidade); condições nutricionais (tipo de ração e regime de alimentação);

Coleta dos dados: indicar a estratégia que será adotada e os instrumentos necessários para a realização da pesquisa, como questionários, formulários, manuais de tabulação e outros;

Serviços auxiliares: Histologia/Anátomopatologia, Laboratório Clínico e outros Laboratórios;

Planejamento estatístico: definir os procedimentos para tabulação, análise e interpretação dos dados, como o uso de tabelas e outros procedimentos estatísticos.

Referências - Consiste da listagem das publicações utilizadas para a elaboração do trabalho. Apesar de haver uma variedade de estilos para a apresentação das Referências, deve-se obedecer aos Requisitos Uniformes para Originais Submetidos a Revistas Biomédicas do Comitê Internacional de Editores de Revistas Médicas (www.icmje.org);

Anexos - Devem ser anexados ao texto documentos complementares que possam enriquecer e elucidar o projeto, tais como mapas, fotos, quadros, tabelas, modelos de questionários, entrevistas ou qualquer outro material complementar usado na pesquisa;

Cronograma de execução.
Orçamento Detalhado do Projeto de Pesquisa: recursos (humanos, para realizar o experimento e para realizar a pesquisa bibliográfica), fontes de financiamento e seu destino, bem como a forma e o valor da remuneração do pesquisador;

Curriculum vitae do pesquisador principal e dos demais pesquisadores participantes.

\section{Termo de Consentimento Livre e Esclarecido} (TCLE), documento integrante do Protocolo, elaborado pelo pesquisador em linguagem acessível à compreensão dos sujeitos da pesquisa. O TCLE deverá ser obtido após o sujeito da pesquisa ou seu responsável legal estar suficientemente esclarecido de todos os possíveis benefícios, riscos e procedimentos que serão realizados, assim como fornecidas todas as informações pertinentes à pesquisa.

Após a aprovação pelo CEP, que referenda a investigação, deve ser: assinado ou identificado por impressão dactiloscópica, por todos e cada um dos sujeitos da pesquisa ou por seus representantes legais; elaborado em duas vias, sendo uma retida pelo sujeito da pesquisa ou por seu representante legal e uma arquivada pelo pesquisador.

O esclarecimento dos sujeitos da pesquisa deve expressar o cumprimento de cada uma das exigências abaixo:

A justificativa, os objetivos e os procedimentos que serão utilizados na pesquisa;

Os desconfortos e riscos possíveis e os benefícios esperados;

Os métodos alternativos existentes;

A forma de acompanhamento e assistência, assim como seus responsáveis;

A garantia de esclarecimentos, antes e durante o curso da pesquisa, sobre o método, informando a possibilidade de inclusão em grupo controle ou placebo;

A liberdade do sujeito se recusar a participar ou retirar seu consentimento, em qualquer fase da pesquisa, sem penalização alguma e sem prejuízo ao seu cuidado;

A garantia do sigilo que assegure a privacidade dos sujeitos quanto aos dados confidenciais envolvidos na pesquisa;

As formas de ressarcimento das despesas decorrentes da participação na pesquisa;

As formas de indenização diante de eventuais danos decorrentes da pesquisa.

Após o término da pesquisa, seus resultados devem ser divulgados sob a forma de Tema Livre e/ou Artigo Original, cumprindo a resolução do Conselho Federal de Medicina $\mathrm{n}^{\circ}$ 1595/2000.

\section{Experimentação animal}

Após a análise e aprovação do projeto de pesquisa pelos Comitês de Ética em Pesquisa Experimental, dar-se-á início ao ensaio experimental ou experiência piloto, fundamental para amadurecer e definir a investigação, no que concerne à amostra e aos procedimentos ${ }^{6}$. 
Alguns preceitos devem ser observados, destacando-se a facilidade da alimentação, do manuseio, da execução do procedimento técnico e o custo operacional.

Nos biotérios brasileiros três espécies são mais utilizadas para estudo experimental, todas pertencentes aos mamíferos, sendo elas: o rato, animal mais escolhido para pesquisa, pelo porte e pela quantidade; o coelho, pela mansidão e facilidade de manuseio; o cão, pelo porte e constituição anatômica. O pesquisador deve conhecer bem as particularidades do animal com o qual irá trabalhar e respeitar os princípios éticos de experimentação animal ${ }^{7,8}$.

Durante a experiência piloto, o pesquisador aprende a lidar com o animal e treina a técnica a ser empregada. Os diversos procedimentos que compõem o método são analisados e ajustados, como os procedimentos anestésicos (fármacos utilizados e respectivas doses), vias de administração e manutenção da anestesia. O candidato treina a técnica a ser utilizada, até obter a maior uniformidade possível em sua metodização ${ }^{6}$.

A primeira tentativa de normatizar a pesquisa animal, foi proposta pela Cruelty to Animals Act, em Londres, numa época que coincidiu com a descoberta e a prática da anestesia cirúrgica por William T. G. Morton, utilizando éter, em 1846. A partir desta data, os animais passaram a merecer todos os benefícios conquistados e aplicados ao ser humano, principalmente quando da realização de um ato operatório indolor. Alguns tópicos normativos gozam do direito de imutáveis até a presente data: drogas anestésicas de primeira linha são administradas para aliviar a dor; experimentos animais devem ser realizados por pesquisador credenciado; os experimentos, motivados pela evolução da ciência, visam o bem dos seres vivos9.

Somente em 1876, na Inglaterra, foram elaborados os princípios de ética aplicados em benefício da experimentação animal, que vigoram até os dias atuais. A Federação Espírita Brasileira admite que os animais são portadores de um princípio inteligente, alguma manifestação de afeto e uma verdadeira alma em período evolutivo. A Lei Judaica proíbe crueldade para com os animais, que devem ser tratados humanamente, com bondade e compaixão. Ainda conforme esta mesma lei, as experiências com animais somente são permitidas se forem realizadas para o bem da Humanidade e não simplesmente para satisfazer desejos individuais, preceitos que estão descritos no Exodus (23:5) e no Deuteronômio (25:4). O judaísmo também adota o conceito de que tudo criado neste mundo por Deus, foi feito para servir à Humanidade ${ }^{10}$.

Gilmore ${ }^{11}$ descreve que o Movimento do Bem-estar do Animal, no Canadá, fundamenta-se em dois propósitos principais: primeiro, reduzir o sofrimento e o número de animais usados em pesquisa; segundo, sensibilizar cientistas para fazê-los refletir sobre a necessidade de utilizar animais em seus experimentos. Pesquisas estão sendo patrocinadas para desenvolver in vitro o que antes era realizado em animais vivos, contudo o questionamento que fica é até que ponto a tecnologia de substituição de animais não prejudica a evolução da ciência médica.

$\mathrm{Na}$ declaração de Helsinki I, adotada na $18^{\mathrm{a}}$ Assembléia Médica Mundial, realizada em Helsinki (Finlândia), no ano de 1964, foi enunciado no item 1 dos
Princípios Básicos: “A pesquisa clínica deve adaptar-se aos princípios morais e científicos que justificam a pesquisa clínica e deve ser baseada em experiências de laboratório e com animais" 10 .

Para que sejam respeitados as leis e os princípios, foram criadas as Comissões de Ética para Pesquisa em Animais. O primeiro país a criar estas comissões foi a Suécia em 1979. Os Estados Unidos da América adotaram esta prática em 1984, enquanto no Brasil os comitês foram constituídos na década de $90^{12}$. É importante que os membros dessas comissões sejam capazes de avaliar a natureza e as conseqüências que determinado experimento pode trazer. Os membros dos Comitês de Ética em Experimentação Animal, assim como os legisladores, têm a difícil tarefa de conciliar os aspectos éticos com os interesses científicos, legais, econômicos e comerciais ${ }^{7}$.

Existem leis e princípios que regem a experimentação animal, visando reduzir ao mínimo qualquer dor, sofrimento ou estresse imposto aos animais. Este consenso é refletido em legislações tais como Animals (Scientific Procedures) Act no Reino Unido, Animal Welfare Act nos Estados Unidos da América e Council of Europe Directive na Comunidade Européia ${ }^{13-17}$.

Até o presente, decorridos mais de vinte anos, a Lei Federal no $n^{-6.638}$, ainda não foi regulamentada e implantada. Tramita no Congresso Nacional o Projeto de Lei n ${ }^{\circ} 3.064 / 97$, de autoria do Deputado Sérgio Arouca, que dispõe sobre a criação e o uso de animais para atividades de ensino e pesquisa. Deve-se também lembrar do Projeto de Lei no $1.153 / 95$, de autoria do Deputado Sérgio Arouca, cujo texto ameaça a realização de pesquisas em animais, prejudicando ou impedindo o avanço científico e tecnológico $^{10}$. Foi apensado o Projeto de Lei no $1.691 / 03$, de autoria da Deputada Iara Bernardi aos de autoria do Deputado Sérgio Arouca, os quais tramitam em Comissões da Câmara dos Deputados até a presente data.

A Professora Doutora Maria de Lourdes P. Biondo Simões, da Universidade Federal do Paraná, coordenou no ano de 2002 a elaboração do "Ante-projeto Conselho Nacional de Ética em Pesquisa envolvendo Animais (CONEPA)", o qual foi amplamente discutido durante o $8^{\circ}$ Congresso Nacional da SOBRADPEC e Cirurgia 2003, em Belo Horizonte-Minas Gerais.

O Conselho Nacional de Saúde ${ }^{18}$, pelo decreto 93.933 de 14 de janeiro de 1987, aprovou a resolução 01/88 que normatiza a pesquisa na área de saúde. O capítulo II (Aspectos Éticos da Pesquisa em Seres Humanos), artigo 5. ${ }^{\circ}$, parágrafo II cita: “A pesquisa que se realiza em seres humanos deverá desenvolver-se conforme as seguintes bases: estar fundamentada na experimentação prévia realizada em animais, em laboratórios ou em outros fatos científicos". A maioria dos códigos internacionais que tratam das normas de pesquisa na área da saúde contém esses princípios.

O Colégio Brasileiro de Experimentação Animal (COBEA), entidade filiada ao International Council for Laboratory Animal Science (ICLAS), procurando colaborar no aprimoramento das condutas dirigidas à experimentação em animais no país, elaborou vários ítens referentes aos Princípios Éticos da Experimentação Animal ${ }^{19}$ : 
Os direitos dos animais devem ser defendidos por leis, como os direitos dos homens.

As pesquisas com animais são realizadas há milhares de anos e é inegável que trazem benefício para o desenvolvimento da ciência e de novas tecnologias, principalmente na área da saúde.

Os docentes, pós-graduandos, residentes e graduandos de uma Faculdade de Medicina, assim como de graduandos dos cursos da área da saúde, que utilizam animais em seus experimentos, têm por obrigação conhecer e praticar os princípios éticos de proteção aos animais adequados à realização de um trabalho científico, em cumprimento à legislação que dita as normas de pesquisa na área da saúde.

Deve-se ter em mente que o uso de animais em atividades científicas deve ser substituído, sempre que possível por métodos alternativos.

\section{Referências}

1. Freitas CBD, Hossne WS. Pesquisa em seres humanos. In: Campana AO, Padovani CR, Iaria CT, Freitas CBD, Paiva SAR, Hossne WS. Investigação científica na área médica. 1ed. São Paulo: Manole;2001. p 205-19.

2. Brasil. Ministério da Saúde. Conselho Nacional de Saúde. Manual operacional para comitês de ética em pesquisa. Brasília: Editora M S; 2002.

3. Muñoz DR, Fortes PAC. O princípio da autonomia e o consentimento livre e esclarecido. In: Costa SIF, Oselka $\mathrm{G}$, Garrafa V. Iniciação à bioética. Brasília: Conselho Federal de Medicina; 1998. p 53-70.

4. Bicalho GG, Barros Filho AA. Iniciação científica: como elaborar um projeto de pesquisa. Rev Cienc Med. 2003;12:365-73.

5. Dos Reis FB, Ciconelli RM, Faloppa F. Pesquisa científica: a importância da metodologia. Rev Bras Ortop. 2002;37:51-5.

6. Schnaider TB, Souza C. Aspectos éticos da experimentação animal. Rev Bras Anestesiol. 2003;53:278-85.

7. Petroianu A. Aspectos éticos na pesquisa em animais. Acta Cir Bras. 1996;11:157-64.
8. Schossler JE. A escolha, contenção e manuseio de animais de experimentação. Acta Cir Bras. 1993;8:166-8.

9. Pimenta LG, Silva AL. Ética e experimentação animal. Acta Cir Bras. 2001;16:255-60.

10. Goldenberg S. Aspectos éticos da pesquisa com animais. Acta Cir Bras. 2000; 15:193-5.

11. Gilmore A. The use of animals in research. Can Med Assoc J. 1985;132:564-8.

12. Britt D. Ethics, ethical committees and animal experimentation. Nature. 1984; 311:503-6.

13. American College of Emergency Physicians. Animal use in research. Ann Emerg Med.1993;22:265-6.

14. Flecknell PA. Anesthesia of animals for biomedical research. Br J Anaest. 1993; 71:885-94.

15. Montgomery CA. Oncologic and toxicologic research: alleviation and control of pain and distress in laboratory animals. Cancer Bull. 1990;42:230-7.

16. Toth LA, Olson GA. Strategies for minimizing pain and distress in laboratory animals. Lab Animals. 1991; 30:33-9.

17. Von Noorden GK. In defense of animal research. Am J Ophthalmol. 1991;111:367-9.

18. Conselho Nacional de Saúde. Normas de pesquisa em saúde. Bioética 1995;3:137-54.

19. Goldenberg S, Tonini K. Tese experimental no mestrado e no doutorado. In: Rapoport A. Mestrado e doutorado na área de saúde. $1^{\mathrm{a}}$.ed. São Paulo: Pancast; 1997;14764.

\section{Correspondence:}

Taylor Brandão Schnaider

Av. Francisca R. Paula, 289

37550-000 Pouso Alegre-MG

sormanti@uai.com.br
Conflito de interesse: nenhum

Fonte de financiamento: nenhuma

\section{Como citar este artigo:}

Schnaider TB. Ética e pesquisa. Acta Cir Bras. [periódico na Internet] 2008 Jan/Fev;23(1). Disponível em URL: http://www.scielo.br/acb. 